\title{
Long-Term Relations Between Intentions, Planning, and Exercise: A 3-Year Longitudinal Study After Orthopedic Rehabilitation
}

\author{
Tabea Reuter \\ Freie Universität Berlin and University of Konstanz \\ Jochen P. Ziegelmann \\ Freie Universität Berlin and University of Zurich \\ Sonia Lippke and Ralf Schwarzer \\ Freie Universität Berlin
}

\begin{abstract}
Objective: Planning has been hypothesized to operate as a mediator linking intentions to health behaviors. To explore the temporal variation of these constructs and their interrelationships, a long-term study of intentions, planning, and physical activity was conducted. Method: A sample of 328 individuals in orthopedic rehabilitation provided data at five measurement occasions over 3 years after their discharge from rehabilitation. A process-oriented approach combining mediation analysis and latent growth curve (LGC) modeling was applied. Results: The orthopedic rehabilitation led to an initial increase in planning and behavior, followed by a decrease after 6 months and stabilization for the next 2.5 years. Intention revealed a slight but constant decrease for 6 months and remained stable up to 3 years after rehabilitation. The mediation model confirmed planning as mediator between intention and physical activity in former rehabilitation participants. Conclusions: Prior evidence on the mediating role of planning in the intention-behavior relation is corroborated and extended by the present findings at the level of long-term processes. Planning can and should be integrated in rehabilitation treatment programs to facilitate sustainable recovery.
\end{abstract}

Keywords: physical activity, treatment sustainability, planning, intention, mediation

Regular physical activity is helpful to preserve rehabilitation outcomes and improve health. Physical activity reduces the risk for some of the most frequent causes of death, which are diabetes, heart problems, stroke, and some kinds of cancer. Moreover, it is beneficial for several chronic conditions and for preventing health limitations because physical activity helps to control weight and facilitate healthy bones, muscles, and joints (Woolf, 2003). Following an accident or surgery, or as part of treatment of chronic pain conditions, engaging in regular exercise is a recommended approach to rehabilitation and secondary prevention, as it is associated with many health benefits, such as reduced morbidity and mortality, increased functional capacity, and improved quality of life (Russell \& Bray, 2009). As a result, orthopedic rehabilitation not only encourages individuals to perform physical exercise during the rehabilitation treatment, but it motivates persons to maintain their activity after discharge (Russell \& Bray, 2009). Studies have shown that different social-cognitive variables predict exercise intention (Blanchard, Courneya, Rodgers, Daub, \& Knapik, 2002; Courneya, Keats, \& Turner, 2000; Russell \& Bray, 2009; Sullivan et al., 2008) and behavior (Blanchard et al., 2002; Reid et al., 2007). Until now, however, after discharge from rehabilitation,

Tabea Reuter, Department of Psychology, University of Konstanz; Jochen P. Ziegelmann, Department of Health Psychology, Freie Universität Berlin, and Center of Gerontology, University of Zurich; Sonia Lippke and Ralf Schwarzer, Department of Health Psychology, Freie Universität Berlin.

Correspondence concerning this article should be addressed to Tabea Reuter, PhD, Psychological Assessment \& Health Psychology, Department of Psychology, University of Konstanz, P.O. Box 47, 78457 Konstanz, Germany. E-mail: tabea.reuter@uni-konstanz.de little is known about (a) the long-term trajectories of behavior and its predictors, that is, whether changes occur similarly across individuals with different motivational prerequisites, and (b) how different predictors operate to change behavior. This is important to know as this has implications for patient education during the rehabilitation, theoretical understanding of behavior change, and methodological application. Therefore, this study makes an attempt to close this gap.

Change in physical activity and its predictors, such as intention and planning, can be very different across individuals and needs to be researched in detail. The vast majority of prospective studies investigating exercise adherence after rehabilitation focus on examining individual differences based on longitudinal data with two waves of measurement and short follow-up periods of a few weeks or months (Sutton, 2004). Furthermore, behavior is often modeled in a static fashion, meaning that individual differences in previous or baseline levels of predictor variables are used to predict individual differences in behavior at later measurement occasions (e.g., Lippke \& Plotnikoff, 2009). The complex manner in which these factors change cannot be well understood by using these static analysis approaches. Advances in methods for the analysis of change such as latent growth curve (LGC) modeling allow researchers to describe intraindividual change and individual differences in change across multiple occasions of measurement (Bryk \& Raudenbush, 1992; McArdle, 1988; Meredith \& Tisak, 1990; Singer \& Willett, 2003). The current study aims at applying this approach in a rehabilitation setting.

The present study addresses the question of the relationship of changes in social-cognitive variables (such as intention formation and planning) to behavior change and demonstrates an approach 
for advancing from common static models of behavior to truly examining the dynamic features implicitly inherent in most theories of behavior adherence. As noted by Weston, Gore, Chan, and Catalano (2008), structural equation modeling (SEM) is a suitable statistical technique for testing complex theories in rehabilitation psychology. Applying SEM to longitudinal data in the LGC modeling framework, we aim at contributing to a better understanding of change mechanisms by modeling how changes over time in relevant predictors of behavior predict changes in physical activity.

\section{Predictors of Behavior Change}

\section{Behavioral Intentions}

Leading theories on human behavior consider behavioral intentions as the most immediate and important predictor of behavior (e.g., Theory of Reasoned Action; Fishbein \& Ajzen, 1975). Although the construct of intention is indispensable in explaining behavior adherence, its predictive value is limited. Motivation alone does not suffice to change behavior. When trying to translate intentions into behavior, people are faced with various obstacles, such as distractions, forgetfulness, or conflicting bad habits. Intention measures often leave substantial variance in behavior unexplained (Orbell \& Sheeran, 1998; Sheeran, 2002). As a result, research has identified additional postintentional, volitional processes that moderate or mediate the intention-behavior relationship (Abraham, Sheeran, Conner, de Vries, \& Otten, 1999). In contrast to motivational models that mainly focus on behavioral intentions as the most proximal antecedents of behavior, volitional models propose self-regulation strategies and cognitions that facilitate the translation of intentions into actual behavior. A self-regulation strategy that facilitates the successful translation of intentions into action is planning the desired behavior.

\section{Planning Behavior Adherence}

Planning when, where, and how to act can facilitate behavior change; people are more likely to act upon their intentions when generating such a plan. To understand the working mechanisms of planning, one can refer to laboratory research on implementation intentions (cf. Gollwitzer \& Sheeran, 2006, for a review). Plans and implementation intentions are very similar and represent a mental "if-then" association that links the when and where of a situation (if-condition) to a specific action (then-condition; Gollwitzer, 1999). Holding an "if-then" cognition in a critical situation is assumed to lead to an immediate behavioral response without much conscious awareness. It is mediated by increased information processing in terms of enhanced accessibility, detection, and discrimination of critical cues (Webb \& Sheeran, 2007).

\section{Implementation Intentions and Planning}

To date, research has accumulated abundant evidence for the effectiveness of planning when the experimenter provided plans as well as when the plans were generated by the participant (for an overview, see Gollwitzer \& Sheeran, 2006). Evidence suggests that implementation intentions have only a weak effect on longterm changes in exercise adherence among rehabilitation participants (cf. Jackson et al., 2005). However, in another study, self- generated plans predicted physical activity over and above goal intentions for an extensive period of time (up to 12 months; Ziegelmann, Luszczynska, Lippke, \& Schwarzer, 2007). Overall, implementation intentions have been demonstrated to be of substantial importance for physical activity after rehabilitation, mediating the effect of intentions on behavior (Blanchard, 2008; Latimer, Martin Ginis, \& Arbour, 2006).

Sniehotta (2009) argues that self-generated plans, that is, reallife planning, are more complex than plans provided by the researcher in the classic implementation intention paradigm. Therefore, it is not only vital to ask participants whether they had formed a plan or not (e.g., in a study by Orbell and Sheeran, 2000), but it is also important to assess whether self-generated plans may differ in terms of content and/or quality. Especially in longitudinal studies, it is valuable to assess the degree of elaboration of plans for predicting behavior change (for a study in the context of orthopedic rehabilitation, cf. Ziegelmann, Lippke, \& Schwarzer, 2006). Plans may become more complex and detailed over time (e.g., in terms of when, where, how, and with whom to perform the desired behavior) as individuals become more experienced with that behavior. Despite the assumed importance of planning, the hidden assumption that self-regulated behavior change includes intraindividual changes in intention and self-generated planning, which affect exercise adherence, has rarely been examined (cf. Sutton, 2002).

\section{Processes of Behavior Change}

\section{Mediation of the Intention-Behavior Relation}

When the relationship between two variables is partially or totally accounted for by an intervening variable, this variable is called a mediator. Mediation analysis helps to identify intervening variables in the relationship between two variables, such as intention and behavior. Planning is seen as a mediator of the intentionbehavior relationship (e.g., Schwarzer, Luszczynska, Ziegelmann, Scholz, \& Lippke, 2008). This implies that individuals who form an intention will be more likely to engage in planning, and those who do plan will be more likely to engage in the desired behavior. There is ambiguous evidence for the mediating role of planning in the intention-behavior association. Whereas some studies find mediating effects (Norman \& Conner, 2005, Study 2; Schwarzer et al., 2008), others do not (Norman \& Conner, 2005, Study 1; White, Terry, \& Hogg, 1994). However, most studies investigated only cross-sectional or short-term longitudinal relations between intention, planning, and behavior.

To strengthen our understanding of long-term exercise adherence after rehabilitation, more research is needed on social-cognitive predictors and behavior over extended time periods. Models of behavior change suggest that change in behavior can be achieved by changes in cognitions, but such change-change associations are rarely tested (cf. Sutton, 2002). The present study aims at investigating the long-term relations between changes in intention and planning for physical activity adherence after rehabilitation. Furthermore, this study applies LGC modeling for testing the hypothesis that planning mediates the intention-behavior relation. 


\section{Latent Growth Curve Modeling}

Compared to more static analysis techniques, LGC modeling has several advantages. With LGC, intraindividual change can be analyzed regarding its particular trajectory shape, that is, whether the shape is linear, quadratic, or exponential. In addition, LGC is able to examine change without measurement error as it uses only latent variables.

Only a few studies have modeled intraindividual processes with the aim of gaining more insight into how people can be supported to translate their intentions into action. Using LGC models, Sniehotta, Nagy, Scholz, and Schwarzer (2006) found that level and change of volitional self-regulation (action control) were distinct predictors of changes in intentions and physical exercise. Furthermore, Scholz, Nagy, Göhner, Luszczynska, and Kliegel (2009) examined how changes in motivational and volitional predictors are associated with change in dietary and smoking behaviors and their respective intentions. Change in self-efficacy was crucial for change in intention and partly for change in behavior. Change in planning was also partly associated with change in behavior. Change in action control was consistently associated with changes in behavior. These first results give promising insights into individual change-change associations, but the results need to be replicated in different behavioral contexts as well as over longer periods of time (e.g., adopting exercise behavior instead of reducing risk behaviors). Also, they should take into account methodology that allows for interindividual differences in intraindividual change processes. Furthermore and most importantly, to our knowledge no study using LGC was applied to the rehabilitation context so far.

\section{Aims of the Present Study}

A longitudinal study was conducted in which the independent variable, the mediator, and the dependent variables were measured five times over a 3-year period. Latent growth modeling was employed to investigate mediating mechanisms (Cheong, MacKinnon, \& Khoo, 2003). The growth of the independent variable, the growth of the mediator, and the growth of the dependent variable can be viewed as distinctive parallel processes. The growth of intention (independent variable) is hypothesized to predict the growth of planning (mediating variable), which, in turn, predicts the growth of physical activity (outcome variable).

\section{Method}

\section{Participants and Procedure}

The study was performed in accordance with the Helsinki Declaration and according to the Proposals for Safeguarding Good Scientific Practice by the German Research Foundation. Study participants were recruited at the reception desk of an orthopaedic rehabilitation center. Individuals with musculoskeletal afflictions such as joint diseases and injuries were admitted to a 3-week rehabilitation outpatient program. Rehabilitation included exercise therapy supervised by sport therapists and the medical team as well as exercise counseling. Individuals were recommended to engage in regular physical activity after discharge and received informa- tion about the benefits of physical activity. Initially, 585 individuals signed up for a study that was advertised to examine exercise adherence and self-regulatory problems. After providing informed consent, participants were assessed at five measurement occasions after discharge: two telephone follow-up assessments at 2 weeks, Time 1 (T1), $n=585$, and 4 weeks, Time 2 (T2), $n=572,97.8 \%$, and three postal follow-ups at 6 months, Time 3 (T3), $n=495,84.6 \%, 12$ months, Time 4 (T4), $n=371,63.4 \%$, and 36 months, Time 5 (T5), $n=328,56.1 \%$. Mean age was 45.9 years, $S D=11.8$; range $18-80$ years, and there were more women, $61.5 \%$, than men. Of the participants, $68.8 \%$ were living with a partner, and $69.2 \%$ were employed.

We examined differences on T1 measures between those persons who withdrew from the study versus those remained across all measurement occasions. No significant differences were found in terms of sex, physical activity, behavioral intention, and planning. For age, a small difference was found $t(632)=4.72, p<.05$, effect size $d=.17$, indicating that remaining participants were slightly older than those who were lost to follow-up, $M_{\text {remaining }}=$ 47.22, $S D_{\text {remaining }}=11.63$ vs. $M_{\text {dropouts }}=45.19, S D_{\text {dropouts }}=$ 11.87

\section{Measures}

All scales were tested in several prior studies with respect to psychometric properties (see Schwarzer et al., 2008; Ziegelmann et al., 2007). The scores of each measure were averaged to indicate a single composite score.

Intention to perform physical activities was assessed with one item: "I intend to exercise for 20 minutes or longer on at least two days per week on a regular basis." Answers were assessed on a four-point scale from 1 (not at all true), 2 (not true), 3 (a little true), to 4 (absolutely true).

Planning was measured with five items. Following the question "How precisely did you plan your twice weekly (or more) exercise lasting at least 20 minutes?" participants rated five statements, e.g., "I have already planned precisely when to exercise," "I have already planned precisely where to exercise," and "I have already planned precisely how to continue exercising even when I feel limited by poor health." The answers ranged from 1 (not at all true), 2 (not true), 3 (a little true), to 4 (absolutely true).

Physical activity was assessed with a modified version of the Godin Leisure-Time Exercise Questionnaire (GLTEQ, Godin \& Shephard, 1985). Three domains of physical activity were taken into consideration: (a) fitness activities, (b) activities to train muscle strength, and (c) game sports, such as volleyball or golf. We assessed (a) how many days did an individual perform the activity in question during the last week, and (b) how many hours and minutes per session did he or she perform the activity. For each domain, physical activity amount was computed by multiplying exercise days per week by minutes per physical activity episode (e.g., Bernstein et al., 1998). The three domains were averaged to a composite score. To deal with the issue of floor effects in count data (Wang, Zhang, McArdle, \& Salthouse, 2008), we categorized the number of minutes per week of strenuous and moderate activity in each activity in five categories $(1=0 \mathrm{~min} / \mathrm{week} ; 2=1$ to 30 $\mathrm{min} /$ week; $3=31$ to $90 \mathrm{~min} /$ week; $4=91$ to $150 \mathrm{~min} /$ week; $5=$ 151 and more min/week). 


\section{Analytic Procedure}

LGC modeling describes pattern of time-ordered observations in an individual with a parsimonious set of parameters (Singer \& Willett, 2003). In such longitudinal models, intraindividual change (e.g., in behavior) may be described by two parameters: an intercept factor that indicates a person's initial level of behavior and a slope parameter indicating the rate of increase or decline in behavior across measurement occasions. LGC models can be used to model a particular shape or form of the change trajectory (e.g., linear, quadratic, exponential) that is assumed to underlie the observed data.

In a growth curve model the same shape of change is invoked for all people; individual differences in intraindividual change are modeled via "random" latent parameters (intercept and slope) that may vary between individuals. This modeling procedure allows examining how people differ in their initial levels of behavior (intercept) or rates of growth or decline over time.

Mediation analysis was conducted following the parallel process LGC modeling procedure proposed by Cheong et al. (2003). In a first step, we investigated how each construct changes over time in separate latent basis LGC models. In a next step, a mediation LGC model was applied to model the long-term relation between the independent variable (intention), the mediator (planning), and the outcome (physical activity). The analyses were conducted using Mplus 5 (Muthén \& Muthén, 2007).

\section{Results}

In a first step, we investigated how each construct changes over time in distinct LGC models. In contrast to the basic (linear) LGC model and its nonlinear extensions (e.g., quadratic, exponential) in which a particular shape of intraindividual change is invoked, the latent basis LGC approach allows modeling the optimal shape of the change trajectories from the observed data (Meredith \& Tisak, 1990).
Table 1 displays estimated parameters from fitting the univariate latent basis LGC models using the Full Informaiton Maximum Likelihood (FIML) method that adjusts for missing data. We assessed the model fit by examining the $\chi^{2}$ test, the comparative fit index (CFI), and the root-mean-square error of approximation (RMSEA). A satisfactory model fit is indicated by a low $\chi^{2}$ value relative to its degrees of freedom $(d f)$, a high CFI $(>.95)$, and a low RMSEA value $(<.05$; Schermelleh-Engel, Moosbrugger, \& Müller, 2003). The overall fit of each of the three univariate models was good. The $\chi^{2}$ statistics were nonsignificant for planning and physical activity, and the CFI as well as the RMSEA were good for intention, $\chi^{2}(7)=21.9, p<.01, \mathrm{CFI}=.97$, RMSEA $=.06$ with $90 \% \mathrm{CI}=(.03, .09)$, planning, $\chi^{2}(7)=8.2, p=.32, \mathrm{CFI}=.99$, RMSEA $=.02$ with $90 \% \mathrm{CI}=(.00, .07)$, and physical activity, $\chi^{2}(7)=10.1, p=.18$; CFI $=.99$, RMSEA $=.03$ with $90 \% \mathrm{CI}=$ $(.00, .08)$. The predicted average (bold line) and individual curves are plotted for physical activity (Figure 1), intention (Figure 2), and planning (Figure 3).

The mean intercept levels and the variances of the growth rate factor were found to be significant. The mean intercept levels of intention, planning, and physical activity were $3.66,3.57$, and 3.50 , respectively, indicating that, on average, individual change in these variables proceeded from these initial baseline levels, measured 2 weeks after discharge from rehabilitation. For physical activity, the basis coefficients of the intraindividual change vectors were estimated as $\mathrm{A}_{1}[t]=[0,-0.27,0.92,1.23,1]$. The values for $\mathrm{T} 1$ and $\mathrm{T} 5$ were constrained to 0 and 1 , respectively. The basis coefficients suggest an intraindividual change pattern characterized by an increase followed by a decrease at 6 months after discharge, and finally a relative stability during the remaining two measurement occasions 1 and 3 years after discharge. The average total amount of growth is given by the mean value of $g_{1}=-0.16$. Thus, the "prototypical" nonlinear intraindividual change pattern is characterized by physical activity levels of 3.5 at the outset, a rise to $\left[(3.50)-0.27^{*}(-0.16)\right]=3.54$ on the second occasion, and a

Table 1

Growth Processes of Intention, Planning, and Behavior

\begin{tabular}{|c|c|c|c|c|c|c|}
\hline \multirow[b]{2}{*}{ Variable } & \multicolumn{2}{|c|}{ Intention } & \multicolumn{2}{|c|}{ Planning } & \multicolumn{2}{|c|}{ Physical activity } \\
\hline & Initial status & Growth rate & Initial status & Growth rate & Initial status & Growth rate \\
\hline \multicolumn{7}{|l|}{ Factor loadings on growth factors } \\
\hline Time 1 & $1^{\mathrm{a}}$ & $0^{\mathrm{a}}$ & $1^{\mathrm{a}}$ & $0^{\mathrm{a}}$ & $1^{\mathrm{a}}$ & $0^{\mathrm{a}}$ \\
\hline Time 2 & $1^{\mathrm{a}}$ & $0.13(0.07)^{\mathrm{b}}$ & $1^{\mathrm{a}}$ & $0.02(0.06)^{\mathrm{b}}$ & $1^{\mathrm{a}}$ & $-0.27(0.62)^{\mathrm{b}}$ \\
\hline Time 3 & $1^{\mathrm{a}}$ & $0.80(0.09)^{\mathrm{b}}$ & $1^{\mathrm{a}}$ & $0.71(0.08)^{\mathrm{b}}$ & $1^{\mathrm{a}}$ & $0.92(0.31)^{\mathrm{b}}$ \\
\hline Time 4 & $1^{\mathrm{a}}$ & $0.98(0.11)^{\mathrm{b}}$ & $1^{\mathrm{a}}$ & $0.77(0.08)^{\mathrm{b}}$ & $1^{\mathrm{a}}$ & $1.23(0.44)^{\mathrm{b}}$ \\
\hline \multirow[t]{2}{*}{ Time 5} & $1^{\mathrm{a}}$ & $1^{\mathrm{a}}$ & $1^{\mathrm{a}}$ & $1^{\mathrm{a}}$ & $1^{\mathrm{a}}$ & $1^{\mathrm{a}}$ \\
\hline & $M$ & Variance & $M$ & Variance & $M$ & Variance \\
\hline \multicolumn{7}{|l|}{ Growth factors } \\
\hline Initial status & 3.66 & 0.36 & 3.57 & 0.26 & 3.50 & 1.15 \\
\hline Growth rate & -0.30 & 0.53 & -0.65 & 0.56 & -0.16 & 0.52 \\
\hline Covariance between growth factors & \multicolumn{2}{|c|}{$-0.19(0.05)^{\mathrm{b}}$} & \multicolumn{2}{|c|}{$-0.11(0.05)^{\mathrm{b}}$} & \multicolumn{2}{|c|}{$-0.38(0.25)^{\mathrm{b}}$} \\
\hline \multicolumn{7}{|l|}{ Residual variances } \\
\hline Time 1 & \multicolumn{2}{|c|}{$0.26(0.04)^{\mathrm{b}}$} & \multicolumn{2}{|c|}{$0.27(0.04)^{\mathrm{b}}$} & \multicolumn{2}{|c|}{$1.40(0.25)^{\mathrm{b}}$} \\
\hline Time 2 & \multicolumn{2}{|c|}{$0.34(0.03)^{\mathrm{b}}$} & \multicolumn{2}{|c|}{$0.39(0.04)^{\mathrm{b}}$} & \multicolumn{2}{|c|}{$0.98(0.38)^{\mathrm{b}}$} \\
\hline Time 3 & \multicolumn{2}{|c|}{$0.37(0.04)^{\mathrm{b}}$} & \multicolumn{2}{|c|}{$0.48(0.06)^{\mathrm{b}}$} & \multicolumn{2}{|c|}{$1.74(0.20)^{\mathrm{b}}$} \\
\hline Time 4 & \multicolumn{2}{|c|}{$0.39(0.05)^{\mathrm{b}}$} & \multicolumn{2}{|c|}{$0.42(0.06)^{\mathrm{b}}$} & \multicolumn{2}{|c|}{$1.53(0.26)^{\mathrm{b}}$} \\
\hline Time 5 & \multicolumn{2}{|c|}{$0.50(0.06)^{\mathrm{b}}$} & \multicolumn{2}{|c|}{$0.50(0.09)^{\mathrm{b}}$} & \multicolumn{2}{|c|}{$2.13(0.27)^{\mathrm{b}}$} \\
\hline
\end{tabular}

${ }^{\mathrm{a}}$ Parameter fixed in the model. ${ }^{\mathrm{b}}$ Unstandardized parameter estimate with the standard error of estimate in parentheses. 


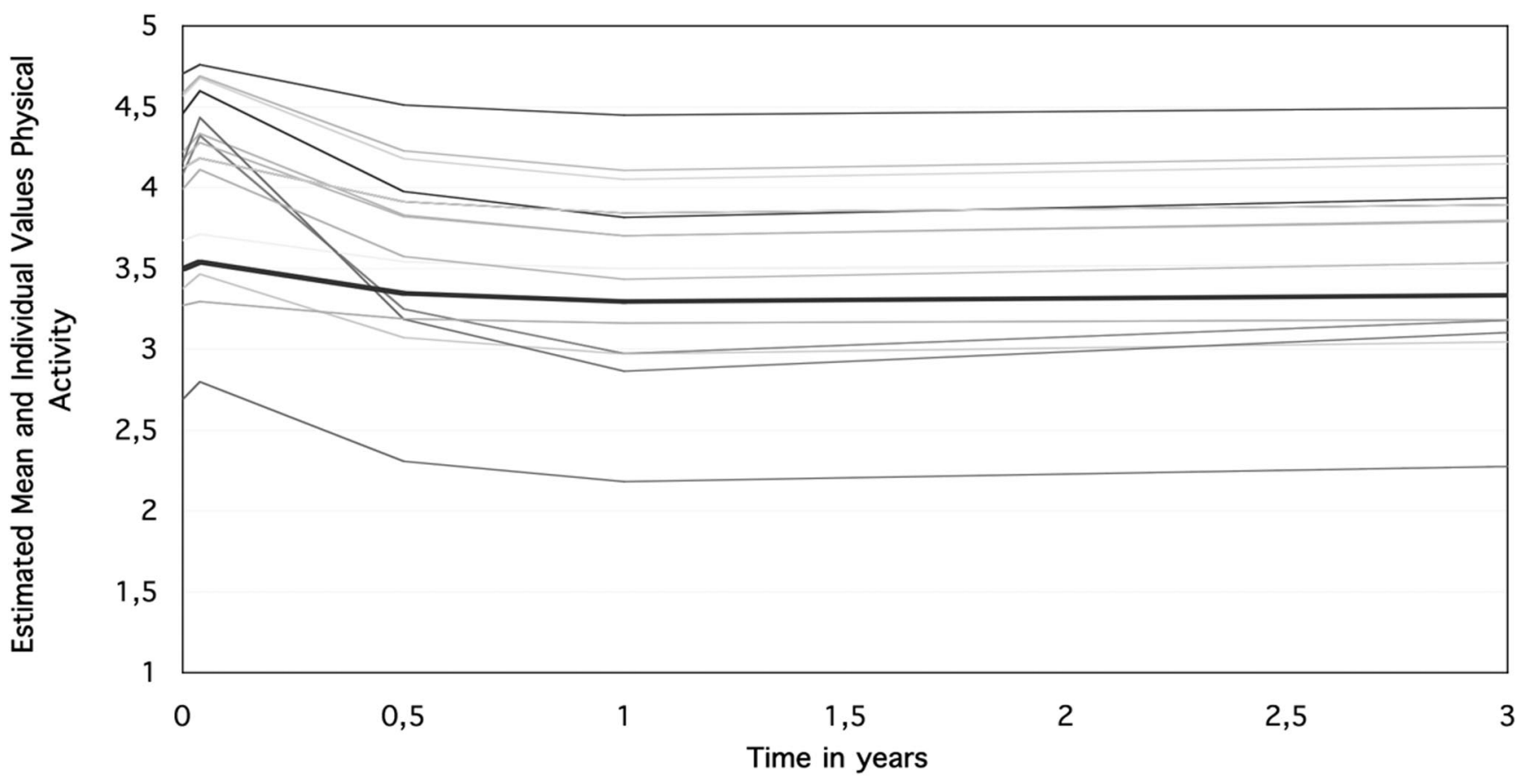

$\longrightarrow$ Estimated Means — $\quad$ Estimated Individual Values

Figure 1. Predicted average (bold lines) and predicted intraindividual changes for 20 randomly selected individuals in physical activity derived from a fitted latent growth curve (LGC) model.

decrease and leveling off after 3 years $[3.50-0.16]=3.34$. For an illustration, this pattern of intraindividual change, as well as the predicted trajectories for 20 randomly drawn individuals, are plotted in Figure 1. The functional form of intraindividual change was expected to be the same for all participants. This assumption implies that all participants' physical activity levels increase and decrease over time in the same way, only the degree of the increase and decrease as well as the baseline level may differ between

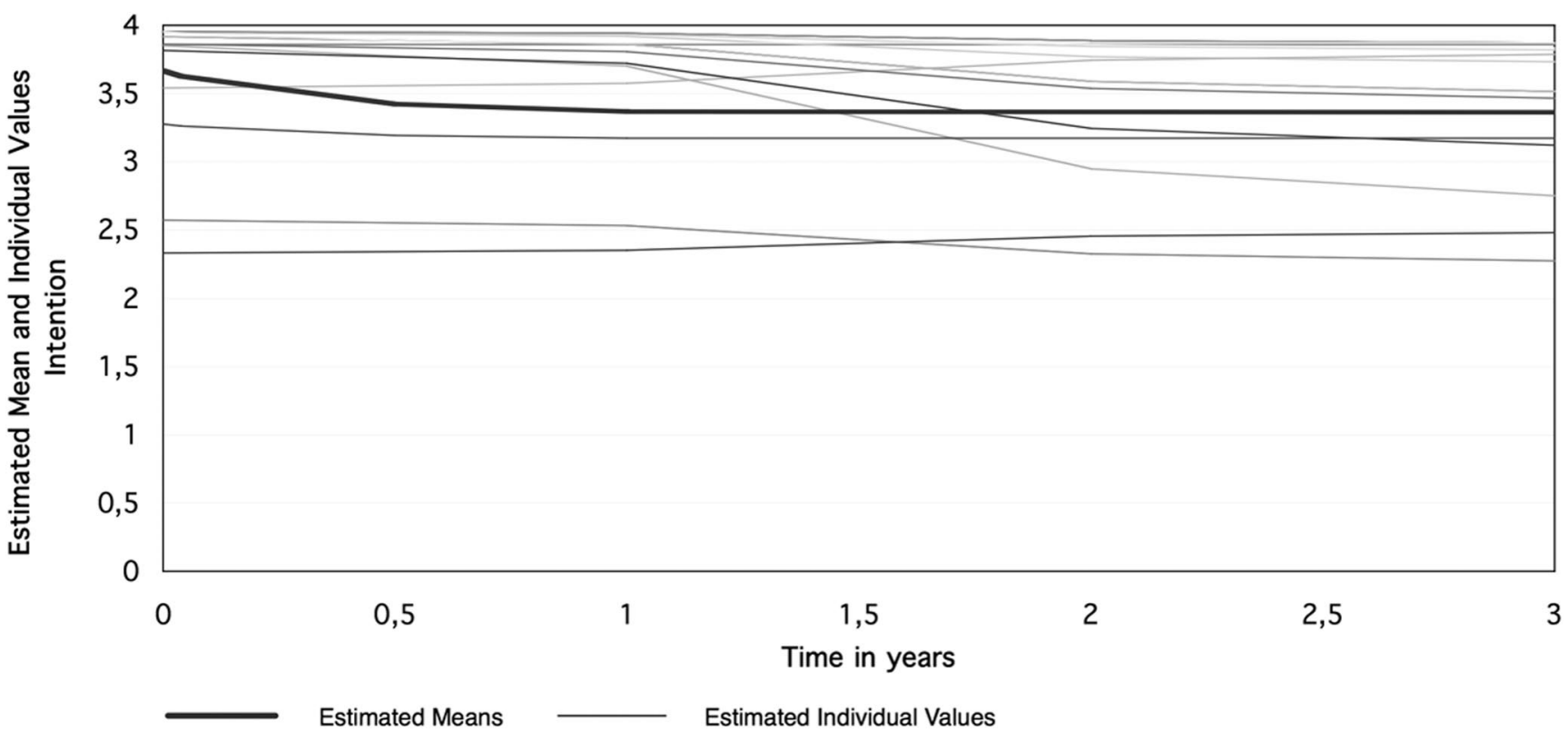

Figure 2. Predicted average (bold lines) and predicted intraindividual changes for 20 randomly selected individuals in intention derived from a fitted latent growth curve (LGC) model. 


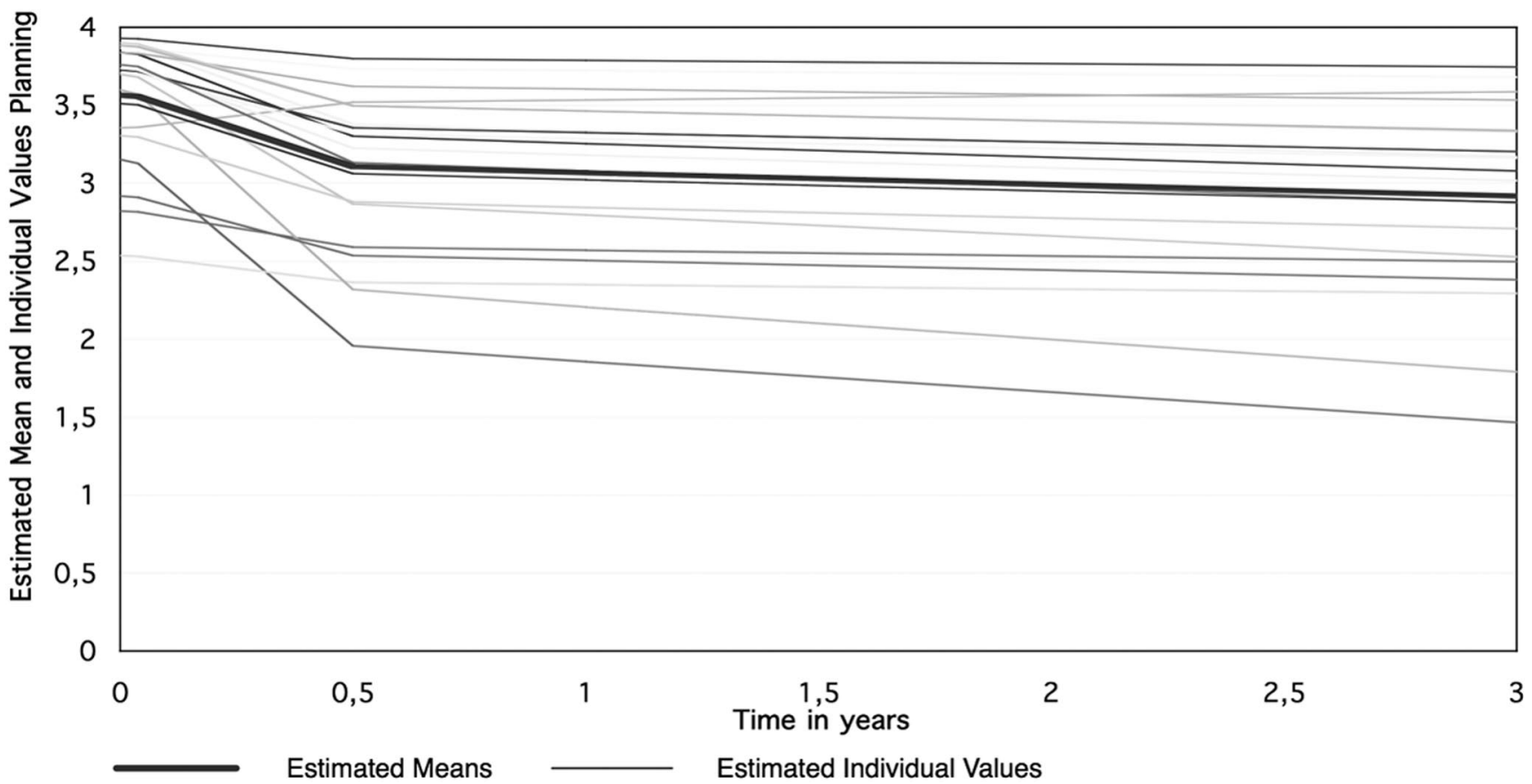

Figure 3. Predicted average (bold lines) and predicted intraindividual changes for 20 randomly selected individuals in planning derived from a fitted latent growth curve (LGC) model.

persons. Stated differently, from their individual baseline levels, change in physical activity proceeds via the same nonlinear "process" for all individuals, with individuals only differing in the expansiveness of physical activity levels.

\section{Mediation Growth Model}

The latent growth model for intention (independent variable), planning (mediating variable), and physical activity (dependent variable) were combined into one latent growth model. This mediation or parallel process LGC model tests the long-term relation among growth factors of the independent variable (intention), the mediator (planning), and the outcome (physical activity). The trajectory shapes were specified in the same manner as in the distinct univariate growth models. The mediation process can be modeled as the trajectory of intention predicting the trajectory of planning, which, in turn, predicts the trajectory of physical activity. The direct path from the slope of intention was nonsignificant and, therefore, was removed from the model. Residuals of the measures intention, planning, and physical activity were allowed to covary with each other at the same measurement occasion. Residuals of the same measures collected repeatedly across time were uncorrelated. For clarity, intercepts and residuals are not depicted in the figure. The model depicted in Figure 4 fits the data well, $\chi^{2}(76)=97.7, p=.05, \mathrm{CFI}=.98, \mathrm{RMSEA}=.03$ with $90 \%$ $\mathrm{CI}=(.00, .04)$. Parameter estimates can be found in Table 2 . The model implies a mediational process in such a way that change in intention led to positive change in planning over time, which, in turn, led to positive change in physical activity over time. The product of coefficients method (e.g., MacKinnon, Lockwood, Hoffman, West, \& Sheets, 2002) was used to obtain the point estimate of the mediated effect, which was 0.60 , and the estimated standard error of the mediated effect based on the first-order solution was 0.15 , indicating a significant mediated effect, $z=$ 4.02, $p<.001$.

\section{Discussion}

The aim of this study was to examine psychological mechanisms in the long-term adherence of physical activity after rehabilitation. As prior research suggests that planning mediates between intentions and behavior, we have examined trajectories of behavior and its most proximal predictors as well as their longterm relations. This was tested by following up individuals for 3 years after rehabilitation. Combining mediation analysis and LGC modeling we have demonstrated that planning can operate as a mediator of the intention-behavior relationship not only on a

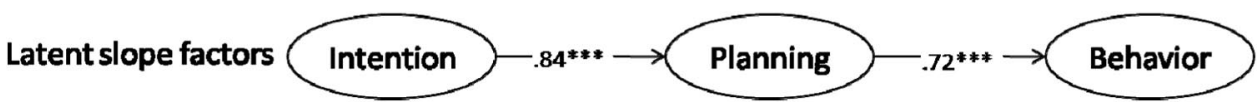

Figure 4. Mediation latent growth curve (LGC) model with standardized parameter estimates. Circles represent latent variables; one-headed arrows are regression paths. Note. ${ }^{* * *} p<.001$. 
Table 2

Parameter Estimates in the Mediation Model

\begin{tabular}{|c|c|c|c|c|c|c|c|}
\hline \multirow[b]{2}{*}{ Variable } & & \multicolumn{2}{|c|}{$\begin{array}{c}\text { Intention (independent } \\
\text { variable) }\end{array}$} & \multicolumn{2}{|c|}{ Planning (mediator) } & \multicolumn{2}{|c|}{$\begin{array}{c}\text { Physical activity (dependent } \\
\text { variable) }\end{array}$} \\
\hline & & Initial status & Growth rate & Initial status & Growth rate & Initial status & Growth rate \\
\hline \multicolumn{8}{|c|}{ Factor loadings on growth factors } \\
\hline Time 1 & & $1^{\mathrm{a}}$ & $0^{\mathrm{a}}$ & $1^{\mathrm{a}}$ & $0^{\mathrm{a}}$ & $1^{\mathrm{a}}$ & $0^{\mathrm{a}}$ \\
\hline Time 2 & & $1^{\mathrm{a}}$ & $0.12(0.09)^{\mathrm{b}}$ & $1^{\mathrm{a}}$ & $-0.004(0.06)^{\mathrm{b}}$ & $1^{\mathrm{a}}$ & $-0.03(0.17)^{\mathrm{b}}$ \\
\hline Time 3 & & $1^{\mathrm{a}}$ & $0.72(0.12)^{\mathrm{b}}$ & $1^{\mathrm{a}}$ & $0.68(0.07)^{\mathrm{b}}$ & $1^{\mathrm{a}}$ & $0.42(0.20)^{\mathrm{b}}$ \\
\hline Time 4 & & $1^{\mathrm{a}}$ & $1.01(0.15)^{\mathrm{b}}$ & $1^{\mathrm{a}}$ & $0.75(0.08)^{\mathrm{b}}$ & $1^{\mathrm{a}}$ & $0.66(0.23)^{\mathrm{b}}$ \\
\hline \multirow[t]{2}{*}{ Time 5} & & $1^{\mathrm{a}}$ & $1^{\mathrm{a}}$ & $1^{\mathrm{a}}$ & $1^{\mathrm{a}}$ & $1^{\mathrm{a}}$ & $1^{\mathrm{a}}$ \\
\hline & $M$ & \multicolumn{2}{|r|}{ Variance } & $M$ & $\underline{\text { Variance }}$ & $M$ & Variance \\
\hline \multicolumn{8}{|l|}{ Growth factors } \\
\hline Initial status & 3.66 & & 0.30 & 3.56 & 0.26 & 3.52 & 0.91 \\
\hline Growth rate & -0.34 & & 0.38 & -0.27 & 0.18 & 0.09 & 0.30 \\
\hline \multicolumn{8}{|l|}{ Residual variances } \\
\hline Time 1 & \multicolumn{3}{|c|}{$0.28(0.03)^{\mathrm{b}}$} & \multicolumn{2}{|c|}{$0.28(0.04)^{\mathrm{b}}$} & \multicolumn{2}{|c|}{$1.52(0.14)^{\mathrm{b}}$} \\
\hline Time 2 & \multirow{2}{*}{\multicolumn{3}{|c|}{$\begin{array}{l}0.29(0.03)^{\mathrm{b}} \\
0.40(0.04)^{\mathrm{b}}\end{array}$}} & \multirow{2}{*}{\multicolumn{2}{|c|}{$0.37(0.04)^{\mathrm{b}}$}} & \multicolumn{2}{|c|}{$1.32(0.14)^{b}$} \\
\hline Time 3 & & & & & & \multicolumn{2}{|c|}{$1.77(0.18)^{\mathrm{b}}$} \\
\hline Time 4 & \multicolumn{3}{|c|}{$0.35(0.06)^{\mathrm{b}}$} & \multicolumn{2}{|c|}{$0.43(0.06)^{\mathrm{b}}$} & \multirow{2}{*}{\multicolumn{2}{|c|}{$\begin{array}{l}1.72(0.22)^{\mathrm{b}} \\
1.84(0.30)^{\mathrm{b}}\end{array}$}} \\
\hline Time 5 & \multicolumn{3}{|c|}{$0.50(0.06)^{\mathrm{b}}$} & \multicolumn{2}{|c|}{$0.47(0.09)^{\mathrm{b}}$} & & \\
\hline
\end{tabular}

Covariance between intercepts

Unstandardized regression coefficients

$\begin{array}{lllll}\text { Growth physical activity on growth planning } & 0.71(0.25)^{\mathrm{b}} & \text { Intention-Planning } & 0.24(0.03) & \text { Intention-Physical activity } \\ \text { Growth planning on growth intention } & 1.07(0.20)^{\mathrm{b}} & \text { Planning-Physical activity } & 0.34(0.05) & \end{array}$

${ }^{a}$ Parameter fixed in the model. ${ }^{\mathrm{b}}$ Unstandardized parameter estimate with the standard error of estimate in parentheses.

short-term basis over a few weeks or months (e.g., Norman \& Conner, 2005, Study 2; Schwarzer et al., 2008), but also across 3 years. Therefore, the main contribution of the present study lies in the extension of the mediator model into a mediation growth model that models long-term changes in intention, planning, and behavior and their interrelations over a 3-year time period.

Recent methodological advances of analyzing longitudinal data allow examining some longstanding questions in health behavior change theory about dynamic relationships (i.e., change-change relationships) instead of static ones (i.e., status-status relationships). In this way, intraindividual processes were identified as well as interindividual differences in intraindividual change and their predictors. Change can only be examined when the behavioral phenomenon under study reveals substantive change variance. Therefore, the investigated sample was suitable for the study of physical activity after discharge from rehabilitation. By investigating long-term change and long-term relations between behavioral predictors and behavior itself, we follow Nesselroade, Stigler, and Baltes, who "[...] believe that research on change processes will best be served by theoretical concepts and empirical inquiry extending beyond the two-occasion case [...]" (1980, p. 635).

Our change model included changes in intention and planning that accounted for a significant amount of variance in behavior change over and above differences in baseline levels. In line with our assumptions, change in intention was an important predictor of change in planning. Change in planning, in turn, predicted change in physical activity. This is in line with previous research on the mediating role of planning in the intention-behavior relation that was found in rehabilitation settings before (e.g., Blanchard, 2008; Schwarzer et al., 2008). The current study has the advantage of employing a latent model that is specified without measurement error.
Theories of behavior adherence are often not explicit in terms of expected interindividual differences in intraindividual change in intention, planning, and behavior. We have attempted to analyze intraindividual change and interindividual differences in change in behavior and its predictors. Expecting more changes in physical activity taking place immediately after discharge from rehabilitation, we used a research design with a high resolution shortly after rehabilitation ( 2 and 4 weeks after discharge) and follow-ups 6, 12, and 36 months after rehabilitation to study long-term changes in physical activity and its predictors. We found that a life event such as orthopedic rehabilitation leads to an initial increase in selfregulation strategies and behavior that levels off after 6 months and stabilizes over the next 2.5 years. Regarding the long-term maintenance of behavior change, only those who were highly motivated and employed self-regulation strategies such as planning after discharge kept up their physical activity levels.

There are limitations to the present study. Data on physical activity were self-reported and thus might be biased. However, in a meta-analysis of 147 studies, Prince et al. (2008) report an average correlation of .47 between self-reported physical activity and direct measures of activity (e.g., doubly labeled water, accelerometry). A correlation of this size indicates that both self-reports and objective data have their own limitations and tap different facets of the phenomenon being measured (Prince et al., 2008). In future studies, enhancement of self-reported behavior by objective measures is needed. Moreover, the present study is not experimental and does not allow for causal inferences. Experimental causal chain designs would be an option to examine the intention-behavior mediation by planning (Reuter, Ziegelmann, Wiedemann, \& Lippke, 2008). Implementing experimental-causal-chain designs with repeated measurement that allows analyzing change can open a new conceptual and methodological door to the study of adherence 
after rehabilitation. The combination of experimental and longitudinal data is ideal for examining temporal aspects of health behavior change.

Nevertheless, the present study is innovative because it extends the well-known mediator model by a temporal and intraindividual perspective. Planning was found to be a mediator of the intentionbehavior relation when examining differences in intraindividual change across three years. This finding has implications for rehabilitation practice in the sense that planning has to be addressed more explicitly during the rehabilitation program (Luszczynska, 2006). Only if individuals have planned when, where, and how to exercise after discharge, they are more likely to act upon their goals.

\section{References}

Abraham, C., Sheeran, P. P. N., Conner, M., de Vries, N., \& Otten, W. (1999). When good intentions are not enough: Modeling postdecisional cognitive correlates of condom use. Journal of Applied Social Psychology, 29, 2591-2612.

Bernstein, M., Sloutskis, D., Kumanyika, S., Sparti, A., Schutz, Y., \& Morabia, A. (1998). Data-based approach for developing a physical activity frequency questionnaire. American Journal of Epidemiology, 147, 147-154.

Blanchard, C. (2008). Understanding exercise behaviour during homebased cardiac rehabilitation: A theory of planned behaviour perspective. Canadian Journal of Physiology and Pharmacology, 86, 8-15.

Blanchard, C. M., Courneya, K. S., Rodgers, W. M., Daub, B., \& Knapik, G. (2002). Determinants of exercise intention and behavior during and following phase II cardiac rehabilitation: An application of the theory of planned behavior. Rehabilitation Psychology, 47, 308-323.

Bryk, A. S., \& Raudenbush, S. W. (1992). Hierarchical linear models: Applications and data analysis methods. Newbury Park, CA: Sage.

Cheong, J., MacKinnon, D., \& Khoo, S. (2003). Investigation of mediational processes using parallel process latent growth curve modeling. Structural Equation Modeling, 10, 238-262.

Courneya, K. S., Keats, M. R., \& Turner, A. R. (2000). Social cognitive determinants of hospital based exercise in cancer patients following high dose chemotherapy and bone marrow transplantation. International Journal of Behavioral Medicine, 7, 189-203.

Fishbein, M., \& Ajzen, I. (1975). Belief, attitude, intention, and behavior: An introduction to theory and research. Reading, MA: Addison-Wesley.

Godin, G., \& Shephard, R. J. (1985). A simple method to assess exercise behavior in the community. Canadian Journal of Applied Sport Sciences, 10, 141-146.

Gollwitzer, P. M. (1999). Implementation intentions: Strong effects of simple plans. American Psychologist, 54, 493-503.

Gollwitzer, P. M., \& Sheeran, P. (2006). Implementation intentions and goal achievement: A meta-analysis of effects and processes. Advances in Experimental Social Psychology, 38, 69-119.

Jackson, C., Lawton, R., Knapp, P., Raynor, D. K., Conner, M., Lowe, C., et al. (2005). Beyond intention: Do specific plans increase health behaviors in patients in primary care? A study of fruit and vegetable consumption. Social Science \& Medicine, 60, 2383-2391.

Latimer, A. E., Martin Ginis, K. A., \& Arbour, K. P. (2006). The efficacy of an implementation intention intervention for promoting physical activity among individuals with spinal cord injury: A randomized controlled trial. Rehabilitation Psychology, 51, 273-280.

Lippke, S., \& Plotnikoff, R. C. (2009). The Protection Motivation Theory within the stages of the Transtheoretical Model-Stage-specific interplay of variables and prediction of stage transitions. British Journal of Health Psychology, 14, 211-229.

Luszczynska, A. (2006). An implementation intentions intervention, the use of planning strategy, and physical activity after myocardial infarction. Social Science and Medicine, 62, 900-908.

MacKinnon, D. P., Lockwood, C. M., Hoffman, J. M., West, S. G., \& Sheets, V. (2002). A comparison of methods to test mediation and other intervening variable effects. Psychological Methods, 7, 83-104.

McArdle, J. J. (1988). Dynamic but structural equation modeling of repeated measures data. In J. R. Nesselroade \& R. B. Cattell (Eds.), Handbook of multivariate experimental psychology (Vol. 2, pp. 561614). New York: Plenum Press.

Meredith, W., \& Tisak, J. (1990). Latent curve analysis. Psychometrika, 55, 107-122.

Muthén, L. K., \& Muthén, B. O. (2007). MPlus user's guide-5th edition. Los Angeles, CA: Muthén \& Muthén.

Nesselroade, J., Stigler, S., \& Baltes, P. B. (1980). Regression toward the mean and the study of change. Psychological Bulletin, 88, 622-637.

Norman, P., \& Conner, M. (2005). The Theory of Planned Behavior and exercise: Evidence for the mediating and moderating roles of planning on intention-behavior relationships. Journal of Sport \& Exercise Psychology, 27, 488-504.

Orbell, S., \& Sheeran, P. (1998). "Inclined abstainers": A problem for predicting health-related behaviour. British Journal of Social Psychology, 37, 151-165.

Orbell, S., \& Sheeran, P. (2000). Motivational and volitional processes in action initiation: A field study of the role of implementation intentions. Journal of Applied Social Psychology, 30, 780-797.

Prince, S. A., Adamo, K. B., Hamel, M. E., Hardt, J., Gorber, S. C., \& Tremblay, M. (2008). A comparison of direct versus self-report measures for assessing physical activity in adults: A systematic review. International Journal of Behavioral Nutrition and Physical Activity, 5, 56. doi:10.1186/1479-5868-5-56

Reid, R., Tulloch, H., Kocourek, J., Morrin, L., Beaton, L., Papadakis, S., et al. (2007). Who will be active? Predicting exercise stage transitions after hospitalization for coronary artery disease. Canadian Journal of Physiology and Pharmacology, 85, 17-23.

Reuter, T., Ziegelmann, J. P., Wiedemann, A. U., \& Lippke, S. (2008) Dietary planning as a mediator of the intention-behavior relation: An experimental-causal-chain design. Applied Psychology: An International Review Special Issue: Health and Well-Being, 57, 194-207.

Russell, K. L., \& Bray, S. R. (2009). Self-determined motivation predicts independent, home-based exercise following cardiac rehabilitation. Rehabilitation Psychology, 54, 150-156.

Schermelleh-Engel, K., Moosbrugger, H., \& Müller, H. (2003). Evaluating the fit of structural equation models: Test of significance and descriptive goodness-of-fit measures. Methods of Psychological Research-Online, 8, 23-74.

Scholz, U., Nagy, G., Göhner, W., Luszczynska, A., \& Kliegel, M. (2009). Changes in self-regulatory cognitions as predictors of changes in smok ing and nutrition behaviour. Psychology and Health, 24, 545-561.

Schwarzer, R., Luszczynska, A., Ziegelmann, J. P., Scholz, U., \& Lippke, S. (2008). Social-cognitive predictors of physical exercise adherence: Three longitudinal studies in rehabilitation. Health Psychology, 27, S54-S63.

Sheeran, P. (2002). Intention-behavior relations: A conceptual and empirical review. European Review of Social Psychology, 12, 1-36.

Singer, J. D., \& Willett, J. B. (2003). Applied longitudinal data analysis: Modeling change and event occurrence. New York: Oxford University Press.

Sniehotta, F. F. (2009). Towards a theory of intentional behaviour change: Plans, planning, and self-regulation. British Journal of Health Psychology, 14, 261-273.

Sniehotta, F. F., Nagy, G., Scholz, U., \& Schwarzer, R. (2006). The role of action control in implementing intentions during the first weeks of behaviour change. British Journal of Social Psychology, 45, 87-106.

Sullivan, K. A., White, K. M., Young, R. M., Chang, A., Roos, C., \& Scott, 
C. (2008). Predictors of intention to reduce stroke risk among people at risk of stroke: An application of an extended health belief model. Rehabilitation Psychology, 53, 505-512.

Sutton, S. (2002). Testing attitude-behaviour theories using non-experimental data: An examination of some hidden assumptions. European Review of Social Psychology, 13, 293-323.

Sutton, S. (2004). Determinants of health-related behaviours: Theoretical and methodological issues. In S. Sutton, A. Baum, \& M. Johnston (Eds.), The Sage handbook of health psychology (pp. 94-126). London: Sage.

Wang, L., Zhang, Z., McArdle, J. J., \& Salthouse, T. A. (2008). Investigating ceiling effects in longitudinal data analysis. Multivariate Behavioral Research, 43, 476-496.

Webb, T. L., \& Sheeran, P. (2007). How do implementation intentions promote goal attainment? A test of component processes. Journal of Experimental Social Psychology, 43, 295-302.

Weston, R., Gore, Jr., P. A., Chan, F., \& Catalano, D. (2008). An introduction to using structural equation models in rehabilitation psychology. Rehabilitation Psychology, 53, 340-356.
White, K. M., Terry, D. J., \& Hogg, M. A. (1994). Safer safe sex: The roles of attitudes, norms and control factors. Journal of Applied Social Psychology, 24, 2164-2192.

Woolf, A. D. (2003). The bone and joint decade. Strategies to reduce the burden of disease: The bone and joint monitor project. The Journal of Rheumatology, 30, 6-9.

Ziegelmann, J. P., Lippke, S., \& Schwarzer, R. (2006). Adoption and maintenance of physical activity: Planning interventions in young, middle-aged, and older adults. Psychology \& Health, 21, 145-163.

Ziegelmann, J. P., Luszczynska, A., Lippke, S., \& Schwarzer, R. (2007). Are goal intentions or implementation intentions better predictors of health behavior? A longitudinal study in orthopedic rehabilitation. Rehabilitation Psychology, 52, 97-102.

Received June 12, 2009

Revision received September 18, 2009

Accepted September 29, 2009

\section{Call for Nominations: Sport, Exercise, and Performance Psychology}

The Publications and Communications (P\&C) Board of the American Psychological Association and Division 47 (Exercise and Sport Psychology) of the APA have opened nominations for the editorship of Sport, Exercise, and Performance Psychology for the years 2011-2016. The editor search committee is co-chaired by Ed Acevedo, PhD, and Robert Frank, PhD.

Sport, Exercise, and Performance Psychology, to begin publishing in 2011, will publishes papers in all areas of sport, exercise, and performance psychology for applied scientists and practitioners. This journal is committed to publishing evidence that supports the application of psychological principals to facilitate peak sport performance, enhance physical activity participation, and achieve optimal human performance. Published papers include experimental studies, qualitative research, correlational studies, and evaluation studies. In addition, historical papers, critical reviews, case studies, brief reports, critical evaluations of policies and procedures, and position statements will be considered for publication.

Editorial candidates should be available to start receiving manuscripts in July 2010 to prepare for issues published in 2011. Please note that the P\&C Board encourages participation by members of underrepresented groups in the publication process and would particularly welcome such nominees. Self-nominations are also encouraged.

Candidates should be nominated by accessing APA's EditorQuest site on the Web. Using your Web browser, go to http://editorquest.apa.org. On the Home menu on the left, find "Guests." Next, click on the link "Submit a Nomination," enter your nominee's information, and click "Submit."

Prepared statements of one page or less in support of a nominee can also be submitted by e-mail to Molly Douglas-Fujimoto, Managing Director,Educational Publishing Foundation, at mdouglas-fujimoto@ apa.org.

The deadline for accepting nominations is January 31, 2010, when reviews will begin. 